\title{
Plant-based food supplement developing and studying its role in optimizing carbohydrate and fat metabolism of people with diabetes under conditions of agriculture digitization
}

\author{
M.I. Kalimullin, S.S. Sadi, B. Tokhiriyon, V.M. Poznyakovsky, S.S. Andrievskikh \\ Ural State University of Economics, 620144 Yekaterinburg, Russian Federation
}

\begin{abstract}
Under conditions of digital economy, in particular, agriculture and food industry, specialized food products, including biologically active food supplements produced from natural raw materials, are increasingly used to improve nutrition and health, and to maintain quality of life. These products are affordable and efficient in coping with metabolism disorders caused by different diseases. Taking all these factors into account the authors developed a pant-based food supplement aimed at improving metabolism of people with type 2 diabetes. The composition of this specialized product is scientifically based in terms of its ingredients and their active substances biochemical and synergetic properties. The innovative production technology of this biologically active food supplement involves pressing its main ingredients and auxiliary substances into tablets. The tablet form provides accurate dosage, convenient packaging and storage, reliable film coating, which ensures tablet hardness and protection from aggressive exposure. The food supplement properties have been determined, including its nutritional value and functional properties. One tablet includes: ascorbic acid $-8.6 \mathrm{mg}$, chromium $-0.1 \mathrm{mg}$, zinc $-2.3 \mathrm{mg}$, flavonoids $-10 \mathrm{mg}$, tannins $-20 \mathrm{mg}$, manganese $-0.8 \mathrm{mg}$. Clinical trials proved the supplement efficacy and functional properties. People with type 2 diabetes took 1 tablet of phyto-complex twice a day alongside sugar-lowering drugs. After one month they demonstrated lower levels of blood glucose, total cholesterol and triglycerides as well as better overall health and lower body mass index. The obtained data clearly indicate better pancreas functions, improved microcirculation, carbohydrate and fat metabolism normalizing. The article also provides recommendations of the supplement intake for people with type 2 diabetes and glucose tolerance disorders.
\end{abstract}

\section{Introduction}

Under conditions of digital economy, in particular, agriculture and food industry, healthy foods development is one of modern nutritiology priorities. Nutriology is trying to combine accumulated experience of both traditional and scientific medicine [1, 7, 8, 21]. Special attention is paid to the development of specialized products, including biologically active food supplements, as they are the simplest and most effective way of improving people's 
nutrition and health $[5,6,9-11,19,20]$. Type 2 diabetes is one of the most common diseases caused by a carbohydrate and fat metabolism disorder. This disease requires urgent preventive and thorough therapeutic measures, nutrition playing the major role [2-4].

\section{Materials and methods}

The study researched the food supplement raw materials and the finished product. General and specific methods were applied to examine the product quality, safety, efficacy and functional properties. Clinical trials proved the specialized product functional properties and its efficacy for people with type 2 diabetes. Patients took a tablet of the food supplement with food twice a day alongside sugar-lowering drug, Maninil ${ }^{\circledR} 5$, while control group patients took only the drug. The research lasted one month. To assess the product functional properties and its efficacy the researchers used clinical methods of examining body mass dynamics, excess body mass, blood pressure, basal and postprandial glycemia, blood biochemistry.

\section{Discussion of the results}

The present paper provides information about a new plant food supplement: its development, properties and efficacy. The product quantitative and qualitative composition is scientifically based in terms of its ingredients and their active substances properties. The regulated quality indicators, including its nutritional value and functional properties, are determined. Clinical trials are conducted to prove the product efficacy and functional properties. The product composition is shown in table 1 .

Table 1. Biologically active food supplement composition

\begin{tabular}{|c|c|}
\hline Ingredients & Content, mg \\
\hline Bilberry (shoots) & 100 \\
\hline Birch (leaf) & 37.5 \\
\hline $\begin{array}{l}\text { Premix 1-03 (37.5 mg contain: vitamin A-0.2 мг, E-0.9 мг, D-31.35 } \\
\mathrm{mkg}, \mathrm{B} 1-0.19 \mathrm{mg}, \mathrm{B} 2-0.19 \mathrm{mg}, \mathrm{B} 6-0.23 \mathrm{mg}, \mathrm{B}-2.1 \mathrm{mg}, \mathrm{B} 5-0.89 \mathrm{mg} \text {, } \\
\text { B12-0.4 mkg, folic acid-67.5 mkg, biotin-24.6 mkg, C-10.3 mg) }\end{array}$ & 37.5 \\
\hline Lingonberry (leaf) & 35 \\
\hline Artichoke (root) & 25 \\
\hline Hypericum (grass) & 25 \\
\hline Nettle (leaf) & 25 \\
\hline Elecampane (root) & 25 \\
\hline Knot grass (grass) & 25 \\
\hline Peppermint (leaf) & 12.5 \\
\hline Burdock (root extract) & 12.5 \\
\hline Raspberry (leaf extract) & 12.5 \\
\hline
\end{tabular}




\begin{tabular}{|c|c|}
\hline Ginger (root) & 10 \\
\hline Quercetin & 7.5 \\
\hline Rutin & 7.5 \\
\hline Bromeline & 5 \\
\hline Gingko Biloba (extract) & 5 \\
\hline Papain & 5 \\
\hline Sublimated garlic & 5 \\
\hline Zinc oxide & 3.3 \\
Zinc content & 2.3 \\
\hline L-Carnitine & 2.5 \\
\hline Coenzyme Q 10 & 2.5 \\
\hline Manganese sulphate & 2.5 \\
Manganese content & 0.8 \\
\hline Octacosanol & 1.25 \\
\hline Chromium picolinate & 0.83 \\
\hline
\end{tabular}

Ginger, elecampane and artichoke roots, bilberry, raspberry and birch leaves influence metabolism and lower blood sugar level. Burdock extract in combination with L-Carnitine, microelements chromium, manganese and vitamins B improve carbohydrate and fat metabolism. Vitamins C, E, PP, quercetin and gingko biloba extract strengthen blood vessel walls, improve blood microcirculation and reduce blood viscosity. Garlic and hypericum have antimicrobial and immunomodulating activity, prevent immunodeficiency disorders. Hypericum boosts digestion, helps neural tissue regeneration and has choleretic and soothing effect. Lingonberry shows antiseptic and diuretic effects and thus improves kidney function. All the above mentioned phyto-complex active substances contribute both to blood sugar lowering and improving pancreas functioning [12-17, 18$]$.

The innovative tableting technology consists of several production stages (fig. 1). The process of pressing active ingredients and auxiliary substances ensures carefully dosed tablet form production:

Raw materials preparation. Incoming raw materials undergo thorough control according to guidelines for quality assurance. Raw materials are received from the warehouse in weights specified in the technology flow chart and then transported to the factory in closed labeled containers. Identifying labels show a green band;

Raw materials dosing is performed according to the product formula and each ingredient weight is recorded in the technology chart;

Raw materials sieving. All supplement ingredients are sieved separately through a vibrosieve (sieve 4) and loaded into a mixer;

Mixing is performed in a V-shaped mixer for 60 minutes. The obtained mixture is weighed, labeled and recorded in a route sheet. When pressed with a pounder, the dry mixture surface should be homogeneous and free of lumps, inclusions and gloss;

Wet granulation process is performed in an extruder press machine MAKIZ 013-01 through a die with $1 \mathrm{~mm}$ hole diameter. Humidifier weight is $50 \%$ of the dry mass. Purified water is used as a humidifier. Obtained wet granulate must be homogeneous and of 
the same color. When exiting the die, the wet granules temperature must be maximum 400C;

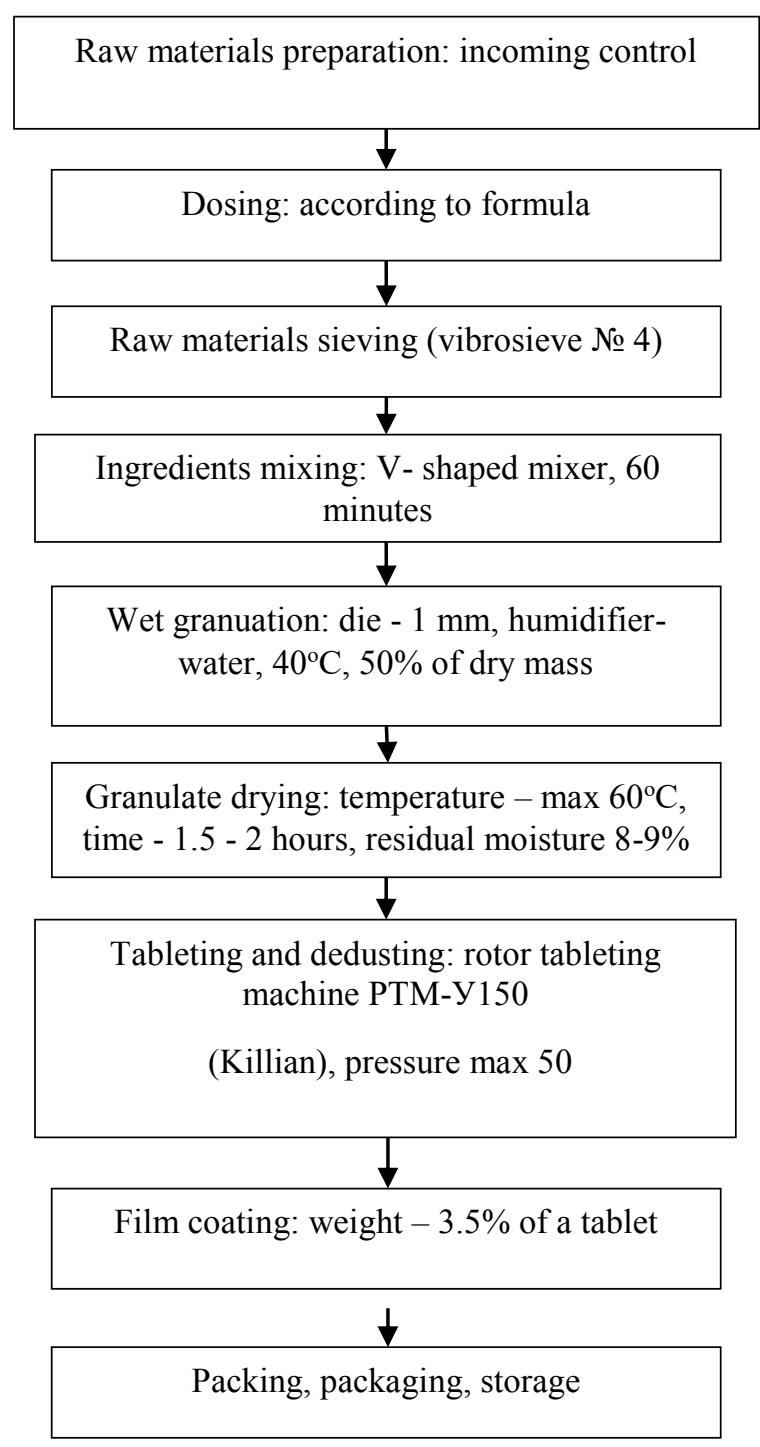

Fig. 1. Product manufacturing technology

Granulate drying is performed in in a desiccator C-105, the maximum temperature being $600 \mathrm{C}$. The optimal drying period is $1.5-2$ hours. The granulate must be periodically stirred up to ensure uniform drying. Residual moisture cannot exceed 8-9\%. Finished mass is put into containers, weighed and labeled. Labels show the product name, its quantity, production date and lot number;

Dry granulation process is carried out with a granulating machine Fitz Mill № 1, 2. Residual moisture, bulk density, fractional composition and flowability are monitored; 
Tableting and tablet dedusting.

Obtained tablet mixture is pressed with a rotor tableting machine PTM-E150 (Killian). The operating pressure is maximum 50n. Tablet appearance is examined: they cannot have chips, cracks, stains, foreign inclusions, stratification and must have smooth surface. The tablet average mass is checked every 30 minutes by weighing 20 tablets and its tensile strength is also examined. Semi-finished product is put into labeled containers. Labels show the product name, its quantity, lot number and production date. Then the product goes to the film coating stage.

Tablet form pressing technology provides accurate dosage of biologically active components. Tablets are convenient to package and store. Special film coating ensures their strength and prevents aggressive exposure to light, moisture, oxygen and carbon dioxide. All the above mentioned factors allow positioning the developed technology as innovative, considering the demand for specialized foods production.

The supplement regulated quality indicators, including nutritional value, are determined following thorough organoleptic, physico-chemical and microbiological studies.

Table 2. Regulated quality indicators

\begin{tabular}{|c|c|}
\hline Quality Indicators & Description and indicator value \\
\hline Appearance & oval tablets with or without film coating \\
\hline Tablet average weight, $g$ & from 0.47 to 0.53 \\
\hline Shell color & white \\
\hline Indicator & Value \\
\hline Disintegration time, minutes, maximum & 30 \\
\hline Under shell color & green (shades with inclusions) \\
\hline Taste and odor & specific \\
\hline Tensile strength , $\mathrm{H}$, minimum & 90 \\
\hline Friability strength, $\%$ minimum & 97 \\
\hline \multicolumn{2}{|c|}{ Nutritional value } \\
\hline Indicator & $\begin{array}{l}\text { Tablet content, mg, } \\
\text { minimum }\end{array}$ \\
\hline Vitamin $\mathrm{C}$ & 8.6 \\
\hline Chromium & 0.1 \\
\hline Zinc & 2.3 \\
\hline Flavonoids & 10 \\
\hline Tannins & 20 \\
\hline Manganese & 0.8 \\
\hline
\end{tabular}

The phyto-complex nutritional value determines its functional properties aimed at optimizing blood glucose level, improving pancreas functioning and supporting metabolism of people with type 2 diabetes. 
Dynamics of blood glucose level before and after meals is studied. Patients who took the phyto-complex demonstrated lower glucose level. This fact testifies of better glucose uptake (fig.2).
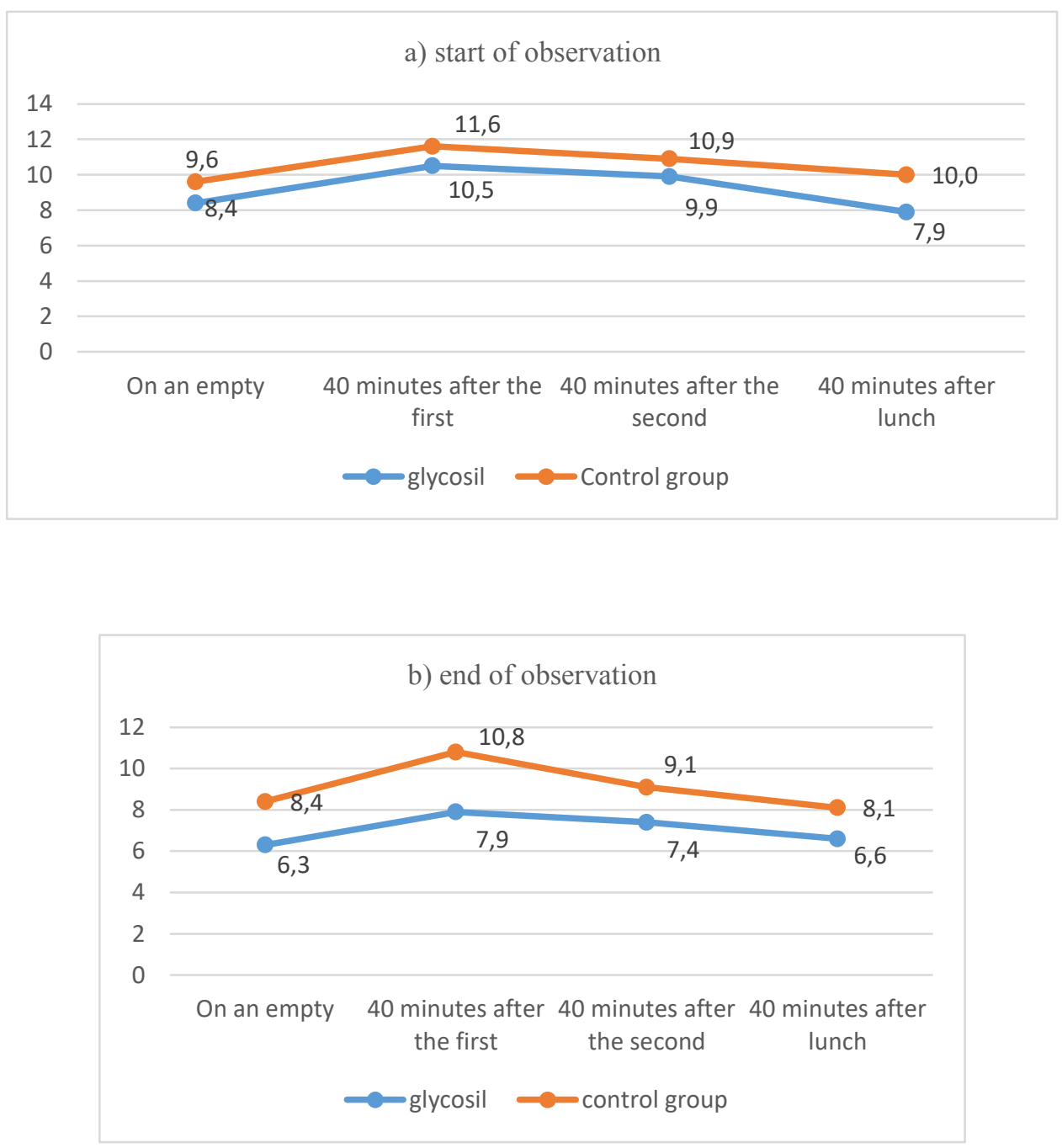

Fig. 2. Dynamics of blood glucose level on an empty stomach and after meals of people with type 2 diabetes, $\mathrm{mcmol} / \mathrm{L}$.

We can observe positive fat metabolism changes. Total cholesterol level decreased by $28 \%$ of the baseline cholesterol. Triglycerides in bloodstream dropped by $23 \%$. Patients reported better overall health, no excessive thirst or dry mouth and, eventually, body mass index reduction by the end of a month observation.

Experts of Russia's Consumer Supervision body and Institute of Nutrition Test Centre of Russia's Academy of Sciences stated that the developed food supplement contributes to blood glucose level optimizing, pancreas and digestion system better functioning, blood microcirculation boosting and carbohydrate and fat metabolism normalizing. 
Recommendations on the phyto-complex intake for people with glucose tolerance disorders and diabetes in order to improve their quality of life and prevent disease complications are developed. Adults are prescribed to take a tablet twice a day with meals for one month (table 3).

Table 3. Essential nutrients content (provided all recommendations are compiled)

\begin{tabular}{|c|c|c|l|c|c|}
\hline Nutrint & $\mathbf{m g}$ & $\begin{array}{c}\text { \% of } \\
\text { DRI }\end{array}$ & Nutrient & mg & \% of DRI \\
\hline Vitamin A & 0.4 & 40 & Vitamin B5 & 1.8 & 36 \\
\hline Vitamin E & 1.8 & 12 & Zinc & 4.6 & 38 \\
\hline Vitamin C & 20.6 & 29 & Biotin & 49.2 & 98 \\
\hline Vitamin B1 & 0.38 & 22 & Vitamin B12 & 0.8 & 27 \\
\hline Vitamin B2 & 0.38 & 19 & Folic acid & 135 & 34 \\
\hline Vitamin B3 & 4.2 & 21 & Vitamin D3 & 2.7 & 54 \\
\hline Vitamin B6 & 0.46 & 23 & - & - & - \\
\hline
\end{tabular}

The product was kept in a dry dark place at room temperature for 39 months to determine its storage life.

36 months later there was no evidence of quality indicator changes, which testifies of the supplement sanitary and epidemiological welfare. 39 months later there appeared slight changes of taste and odor, which helped determine the storage life of 36 months and 3 months' allowance.

The specialized product is certified, received a sanitary - epidemiological conclusion and certificate of BAFS state registration. It is tested and produced by the enterprises of the company "Artlife" (Tomsk), which are certified in accordance with the requirements of international standards of the ISO 9001: 2000 series and GMP rules. This fact ensures the product competitiveness and quality stability.

\section{Conclusions}

The study deals with the digitization issues of specialized products and biologically active food supplements production. Their production involves using natural raw materials and plants. Under conditions of agriculture and food industry digitization the innovative technology of a new specialized plant-based food supplement production was developed. The product is aimed at metabolism multifactorial support. The innovative production technology ensures long shelf life of ingredients and their active substances. Tablet pressing provides accurate dosage of biologically active ingredients. This technology also provides synchronous intracellular delivery of biologically active components. They have different absorption and transportation ways but affect the same body organ at the same time. The other biologically active product substances boost the natural body's defense mechanism and prevent alimentary chronic diseases development. The supplement efficacy was proven by clinical trials when patients with diabetes took it alongside Maninil-5. The trial results are presented in the study. They demonstrate carbohydrate metabolism normalization and pancreas better functions. Nutrition therapy recommendations are also developed. 


\section{References}

1. A. N. Avstrievskikh, A.A. Vekovtsev, V.M. Poznyakovsky, Healthy nutrition products: new technologies, quality assurance, efficacy (Siberian University Publishing House, Novosibirsk, 2005)

2. N.F. Gerasimenko, V.M. Poznyakovsky, N.G. Chelnakova, Human. Sport. Medicine, 1 (17), 79 (2017)

3. Report on non-infectious diseases situation in the world, 2010, WHO executive summary, Geneva, (2011)

4. Russia's health: Atlas, Editied by L.A. Bokeriya, 8th editio (M.: Bakoulev Centre for Cardiovuscular Surgery, Russia's Academy of Sciences, 2012)

5. V.M. Poznyakovsky, Food idustry, 3, 5 (2017)

6. V.M. Poznyakovsky, O.V. Chugunova, M.Yu. Tamova, Food ingredients and biologically active food supplements (M.: INFRA-M, 2017)

7. V.I. Pokrovsky, G.A. Romanenko, V.A. Knyazhev, N.F. Gerasimenko, G.G, Onischenko, V.A. Tutelyan, V.M. Poznyakovsky, Healthy nutrition policy. Federal and regional levels (Siberian Unoversity Publishing House, Novosibirsk, 2002)

8. V.A. Tutelyan, A.P. Nechaeva, Food ingredients in contemporary foods development (M.: DeLi plus, 2014)

9. V.A. Chereshnev, V.M. Poznyakovsky, Food industry, 1 (1), 6 (2016)

10. E.Yu. Lobach, V.M.Poznyakovsky, Food and Raw Materials, 4 (2), 66 (2016)

11. V.G. Popov, S.N.Khabarov, G.D. Kadochnikova, V.M. Poznyakovsky, Int. J.of Applied Engineering Research, 12 (15), 5421 (2017)

12. E. Galgani, Jose \& Cortés, Víctor \& Carrasco, Fernando, Carbohydrate, Fat and Protein Metabolism in Obesity, 1 (2015) doi 10.1007/978-3-319-12125-3_21-1.

13. M.L. Mizgier, M. Casas et al. Obes Rev., 15 (7), 587 (2014)

14. C. Castro, G. Corraze, A. Firmino-Diógenes, L. Larroquet, S. Panserat, A. Oliva-Teles, British Journal of Nutrition, 116 (1), 19 (2016). doi: 10.1017/S000711451600163X.

15. D.S. Ludwig, M.I. Friedman, JAMA, 311, 2167 (2014)

16. Kevin D. Hall et al, Cell Metabolism, 22 (3), 427 (2016)

17. J.L. Ble-Castillo, M.A. Aparicio-Trapala, I.E. Juárez-Rojop, J.E. Torres-Lopez, J.D. Mendez, H. Aguilar-Mariscal, V. Olvera-Hernández, L.C. Palma-Cordova, J.C. DiazZagoya, Int. J. Environ. Res. Public Health, 9, 1663 (2012)

18. B. Tohiriyon, V.M. Poznyakovskii, Proceedings of the Voronezh State University of Engineering Technologies, 80 (3), 185 (2018). https://doi.org/10.20914/2310-12022018-3-185-189.

19. B. Tokhiriyon, V. M. Poznyakovsky, IOP Conference Series: Earth and Environmental Science, 315 (3), 23 (2019)

20. B. Tokhiriyon, V.M. Poznyakovsky, N.M. Beliaev, Int. J. of Pharmaceutical Research \& Allied Sciences, 8 (1), 115 (2019)

21. A.A. Vekovtsev, B. Tokhiriyon, A.A. Chelnakov, V.M. Poznyakovsky, Human. Sport. Medicine, 17 (3), 94 (2017). DOI: 10.14529/hsm170310 